\title{
Skeletal muscle tissue engineering: best bet or black beast?
}

\author{
Barbara Perniconi ${ }^{1,2,3}$ and Dario Coletti ${ }^{1,2,3}$ * \\ ${ }^{1}$ Biology of Adaptation and Aging (B2A), Université Pierre et Marie Curie Paris 6, Paris, France \\ 2 Department of Anatomical, Histological, Forensic Sciences and Hortopedics, Sapienza University of Rome, Rome, Italy \\ ${ }^{3}$ Interuniversity Institute of Myology, Rome, Italy \\ *Correspondence: dario.coletti@snv.jussieu.fr
}

Edited by:

Valentina Di Felice, University of Palermo, Italy

Reviewed by:

Giancarlo Forte, St. Anne's University Hospital Brno, Czech Republic

Valentina Di Felice, University of Palermo, Italy

Keywords: skeletal muscle, stapedius muscle, tissue engineering, $3 \mathrm{~d}$ cell cultures, regenerative medicine

Skeletal muscle possesses a remarkable self-repair capacity whose underlying mechanisms have been thoroughly investigated (Vandenburgh et al., 1988; De Arcangelis et al., 2003; Musaro et al., 2007; Moresi et al., 2008, 2009) with a view to stimulating in situ regeneration. It is, however, unable to restore volumetric tissue loss as a consequence of trauma, congenital defects, ablation, or denervation. This is the rationale behind the creation of new skeletal muscle through tissue engineering (TE). While most review articles announce that skeletal muscle TE is advancing and is readily translatable, it seems clear that engineered skeletal muscle is still lagging far behind other tissues if placed within a clinical practice context. Why is it not yet possible to transplant off-the-shelf, functional muscles into patients?

Major difficulties encountered in skeletal muscle TE on the whole organ scale are currently being addressed. These include the following: the large size of human organs has been overcome by studies on rabbit, dogs and humans (Badylak et al., 1998; Rossi et al., 2010; Badylak et al., 2013); numerous myogenic cell populations of muscle and non-muscle origin (Rossi et al., 2010) are now available as cell sources; scaffolds with a specific 3D orientation are obtained through organ decellularization, freeze drying and electrospinning of synthetic or natural materials (Klumpp et al., 2010); function has been proven for several of these engineered muscle constructs (Mudera et al., 2010; Carosio et al., 2013). Even some of the interactions between muscle and other organs have been addressed: the muscular-tendinous junction can be restored by suturing the residual tendon proximal extremity of muscle-derived acellular scaffolds to the host tendon (Perniconi et al., 2011); the vascular bed can be reconstructed in striated muscles (Koffler et al., 2011; Carosio et al., 2013), particularly if the elegant approach proposed by Ott et al. for decellularized heart is applied (Ott et al., 2008).

Muscles, however, remain very challenging organs to rebuild. Muscle hierarchic architecture and heterogeneous cell composition have not yet been sufficiently investigated by either in vitro or in vivo studies. Moreover, innervation by the somato-motor system has not been addressed at all. We believe that the latter issue will be the hardest to address; since we are still unable to induce normal re-innervation following motor neuron injury, the successful innervation of a new, pre-built organ transplanted in vivo is unlikely to be straightforward. Lastly, even some basic aspects of muscle TE, such as graft bioactivity and integration, which are often claimed to be established, are actually still poorly understood; for instance, the novel idea of cryptic peptides released by the extra-cellular matrix (ECM) while it is being biodegraded and remodeled (Grayson et al., 2009) opens new avenues for the exploration of ECM component bioactivity. This need to gain a better knowledge of the properties of the ECM and bioactive molecules used in TE applications is indeed the rationale of dedicated publications, such as this Frontiers in Muscle Physiology Special Issue.

While obtaining a fully functional, innervated human skeletal muscle from TE that may be used for clinical purposes remains a long-term goal, here we propose two applications for engineered muscle that are no less ambitious and that may be achieved and exploited in the short term. As stated by Grayson et al., the biomimetic effort being made within the context of skeletal muscle TE is mostly aimed at: (a) the creation of functional tissue grafts for regenerative medicine applications in vivo; (b) the generation of experimental models in vitro for studies on stem cells, development, and disease (where engineered tissues can serve as advanced 3D models).

(a) As far as organ replacement in vivo is concerned, we expect very specific TE-based interventions, such as the application of muscle flaps and the generation of minute individual muscles, to be immediately successful, whereas the mass production of large muscles involved in chronic and global muscle wasting diseases is less unlikely to be so. One example of organ replacement that is likely to be successful is the Stapedius, which is the smallest and weakest skeletal muscle in the human body. It stabilizes the stapes, a very small bone in the inner hear, and is innervated by the facial nerve. Dysfunctions in the Stapedius induce hyperacusis or other sound perception defects that are clinically relevant. While the problem of innervation is likely to persist, the engineering and grafting of this small and simple muscle to replace the diseased one (often due to a local defect) appears to be highly feasible.

(b) As far as in vitro studies are concerned, it is self-evident that bidimensional 
cultures are very limited insofar as the physiological 3D tissue organization they yield is somewhat approximate. Muscle TE was initially designed for in vitro studies, when Vandenburgh et al. introduced the $3 \mathrm{D}$ cultivation of primary myoblasts in collagen gel and generated contracting muscle tissue in vitro for the first time in 1988 (Vandenburgh et al., 1988). A progressive increase in the architectural complexity of ECM and cells in tissueculture grade constructs is likely to provide adequate experimental models for the in vitro study of phenomena that are specific to the in vivo situation [e.g., stem cell niche, tissue regeneration, aging (Sharples et al., 2012)].

With regard to the two applications described above, it should be borne in mind that the goals and approaches involved in building engineered muscle tissue may not be the same owing to the significant differences between in vitro and in vivo TE strategies (reviewed by Rossi et al., 2010).

For all these reasons, we believe that the best bet for skeletal muscle TE is to focus on specific, anatomically defined solutions or on $3 \mathrm{D}$ in vitro modeling of muscle tissue for basic and applied research. We are confident that we will eventually be able to transform the black beast (i.e., striated muscle tissue engineering) into the best bet (i.e., a successful clinical practice based on engineered muscles). However, for more ambitious muscle TE applications, there may still be a long way to go.

\section{ACKNOWLEDGMENTS}

Dario Coletti is funded by UPMC Emergence (2011-EME1115), AFM (20120773), and ANR (2013-J13R191). Barbara Perniconi is supported by Calabrodental (in the context of a "PROMETEO Project-Progettazione e Sviluppo di piattaforme tecnologiche innovative ed ottimizzazione di PROcessi per applicazioni in MEdicina rigenerativa)."

\section{REFERENCES}

Badylak, S. F., Dearth, C. L., Rubin, J. P., Ambriosio, F., Boninger, M., Sicari, B. M., et al. (2013). "A biologic scaffold approach to promote functional skeletal muscle in patients with volumetric muscle loss," in Termis-AM Conference: Celebrating 25 Years of Transformative Science and Engineeing. (Atlanta, GA).

Badylak, S. F., Kropp, B., McPherson, T., Liang, H., and Snyder, P. W. (1998). Small intestinal submucosa: a rapidly resorbed bioscaffold for augmentation cystoplasty in a dog model. Tissue Eng. 4, 379-387. doi: 10.1089/ten.199 8.4.379

Carosio, S., Barberi, L., Rizzuto, E., Nicoletti, C., Del Prete, Z., and Musaro, A. (2013). Generation of eX vivo-vascularized Muscle Engineered Tissue (XMET). Sci. Rep. 3:1420. doi: 10.1038/srep01420

De Arcangelis, V., Coletti, D., Conti, M., Lagarde, M., Molinaro, M., Adamo, S., et al. (2003). IGF-I-induced differentiation of L6 myogenic cells requires the activity of cAMPphosphodiesterase. Mol. Biol. Cell 14, 1392-1404. doi: 10.1091/mbc.E02-03-0156

Grayson, W. L., Martens, T. P., Eng, G. M., Radisic, M., and Vunjak-Novakovic, G. (2009). Biomimetic approach to tissue engineering. Semin. Cell Dev. Biol. 20, 665-673. doi: 10.1016/j.semcdb.2008.12.008

Klumpp, D., Horch, R. E., Kneser, U., and Beier, J. P. (2010). Engineering skeletal muscle tissuenew perspectives in vitro and in vivo. J. Cell Mol. Med. 14, 2622-2629. doi: 10.1111/j.1582-4934. 2010.01183.x

Koffler, J., Kaufman-Francis, K., Shandalov, Y., Egozi, D., Pavlov, D. A., Landesberg, A., et al. (2011). Improved vascular organization enhances functional integration of engineered skeletal muscle grafts. Proc. Natl. Acad. Sci. U.S.A. 108, 14789-14794. doi: 10.1073/pnas. 1017825108

Moresi, V., Garcia-Alvarez, G., Pristera, A., Rizzuto, E., Albertini, M. C., Rocchi, M., et al. (2009). Modulation of caspase activity regulates skeletal muscle regeneration and function in response to vasopressin and tumor necrosis factor. PLOS ONE 4:e5570. doi: 10.1371/journal.pone.0005570

Moresi, V., Pristera, A., Scicchitano, B. M., Molinaro, M., Teodori, L., Sassoon, D., et al. (2008). Tumor necrosis factor-alpha inhibition of skeletal muscle regeneration is mediated by a caspase-dependent stem cell response. Stem Cells 26, 997-1008. doi: 10.1634/stemcells.2007-0493

Mudera, V., Smith, A. S., Brady, M. A., and Lewis, M. P. (2010). The effect of cell density on the maturation and contractile ability of muscle derived cells in a $3 \mathrm{D}$ tissue-engineered skeletal muscle model and determination of the cellular and mechanical stimuli required for the synthesis of a postural phenotype. J. Cell. Physiol. 225, 646-653. doi: 10.1002/jcp. 22271

Musaro, A., Giacinti, C., Pelosi, L., Dobrowolny, G., Barberi, L., Nardis, C., et al. (2007). Stem cellmediated muscle regeneration and repair in aging and neuromuscular diseases. Eur. J. Histochem. 51(Suppl 1), 35-43.

Ott, H. C., Matthiesen, T. S., Goh, S. K., Black, L. D., Kren, S. M., Netoff, T. I., et al. (2008). Perfusiondecellularized matrix: using nature's platform to engineer a bioartificial heart. Nat. Med. 14, 213-221. doi: 10.1038/nm1684

Perniconi, B., Costa, A., Aulino, P., Teodori, L., Adamo, S., and Coletti, D. (2011). The promyogenic environment provided by whole organ scale acellular scaffolds from skeletal muscle. Biomaterials 32, 7870-7882. doi: 10.1016/j.biomaterials.2011.07.016

Rossi, C. A., Pozzobon, M., and De Coppi, P. (2010). Advances in musculoskeletal tissue engineering: moving towards therapy. Organogenesis 6, 167-172. doi: 10.4161/org.6.3.12419

Sharples, A. P., Player, D. J., Martin, N. R., Mudera, V., Stewart, C. E., and Lewis, M. P. (2012). Modelling in vivo skeletal muscle ageing in vitro using threedimensional bioengineered constructs. Aging Cell 11, 986-995. doi: 10.1111/j.1474-9726.2012. 00869.x

Vandenburgh, H. H., Karlisch, P., and Farr, L. (1988). Maintenance of highly contractile tissuecultured avian skeletal myotubes in collagen gel. In Vitro Cell. Dev. Biol. 24, 166-174. doi: 10.1007/BF02623542

Conflict of Interest Statement: The authors declare that the research was conducted in the absence of any commercial or financial relationships that could be construed as a potential conflict of interest.

Received: 08 April 2014; paper pending published: 12 June 2014; accepted: 17 June 2014; published online: 04 July 2014.

Citation: Perniconi B and Coletti D (2014) Skeletal muscle tissue engineering: best bet or black beast? Front. Physiol. 5:255. doi: 10.3389/fphys.2014.00255

This article was submitted to Striated Muscle Physiology, a section of the journal Frontiers in Physiology.

Copyright (c) 2014 Perniconi and Coletti. This is an open-access article distributed under the terms of the Creative Commons Attribution License (CC BY). The use, distribution or reproduction in other forums is permitted, provided the original author(s) or licensor are credited and that the original publication in this journal is cited, in accordance with accepted academic practice. No use, distribution or reproduction is permitted which does not comply with these terms. 